\title{
Implication of mitochondria-derived ROS and cardiolipin peroxidation in $\mathrm{N}$-(4-hydroxyphenyl)retinamide-induced apoptosis
}

\author{
A Asumendi*,', MC Morales', A Alvarez', J Aréchaga' and G Pérez-Yarza' \\ 'Department of Cell Biology and Histology, School of Medicine and Dentistry, University of The Basque Country, Leioa- 48940, Bizkaia, Spain
}

\begin{abstract}
We have studied the effect of $\mathrm{N}$-(4-hydroxyphenyl)retinamide on either malignant human leukaemia cells or normal cells and investigated its mechanism of action. We demonstrate that 4HPR induces reactive oxygen species increase on mitochondria at a target between mitochondrial respiratory chain complex I and II. Such oxidative stress causes cardiolipin peroxidation which in turn allows cytochrome $c$ release to cytosol, caspase- 3 activation and therefore apoptotic consumption. Moreover, this apoptotic pathway seems to be bcl-2/bax independent and count only on malignant cells but not normal nor activated lymphocytes.

British Journal of Cancer (2002) 86, 195 I - 1956. doi: I0.1038/sj.bjc.6600356 www.bjcancer.com

(c) 2002 Cancer Research UK
\end{abstract}

Keywords: N-(4-hydroxyphenyl)retinamide; apoptosis; reactive oxygen species; mitochondria; cardiolipin peroxidation; cytochrome c

Recently, retinoids have generated interest as potential therapeutic and preventive agents for the treatment of cancer. Among the synthetic retinoids with minimal clinical toxicity, N-(4-hydroxyphenyl)retinamide (4HPR), also named fenretinide, has emerged as one of the most promising alternatives to the natural-more toxic-retinoids. 4HPR inhibits carcinogenesis and has therapeutic effects in a variety of animal cancer models. Trials in humans are also presently under way with 4HPR (Ulukaya and Wood, 1999). These anticancer activities seem to be related with their ability in vitro to inhibit tumour cell growth and to induce apoptosis (Delia et al, 1993; Kalemkerian et al, 1995). Recently, reactive oxygen species (ROS) have been implicated in the mediation of apoptosis by 4 HPR in human cancer cells (Delia et al, 1997; Maurer et al, 1999; Suzuki et al, 1999; Hail and Lotan, 2001), but at least one mechanism independent to ROS, which involved RAR-mediated pathway, has also been reported to be involved (Sun et al, 1999).

Accumulating evidence points to a central role of mitochondria during apoptosis. Alterations in mitochondrial physiology, such as dissipation of the inner transmembrane potential and/or release of intermembrane proteins through the outer membrane, have been described in many apoptotic responses (Loeffler and Kroemer, 2000). Among the released proteins, caspases (mainly 2, 3 and 9), caspase activators (cytochrome $c$, hsp10) as well as a caspaseindependent death effector AIF (apoptosis inducing factor) have been identified, and they are ultimately responsible for apoptotic cell consumption (Loeffler and Kroemer, 2000).

In this study, we contribute with new data to the mechanisms by which 4HPR induces cell death in cancer cells, involving cardiolipin peroxidation as the cause of cytochrome $c$ release and caspase- 3 activation.

*Correspondence: A Asumendi; E-mail: gcpasmaa@|g.ehu.es;

Received 27 December 200 I; revised 5 April 2002; accepted 9 April 2002

\section{MATERIALS AND METHODS}

\section{Cell cultures and isolation of peripheral lymphocytes}

CCRF-CEM human acute lymphoblastoid leukaemia cells were routinely grown in RPMI 1640 supplemented with 10\% heat inactivated foetal calf serum (FCS), $100 \mu \mathrm{g} \mathrm{ml}^{-1}$ gentamicine and $2 \mathrm{mM}$ L-glutamine. Human peripheral blood mononuclear cells from normal volunteers were obtained after Ficoll-Paque (Pharmacia LKB, Uppsala, Sweden) density gradient centrifugation and differential adhesion. Cells were cultured in 10\% FCS and RPMI 1640 containing L-glutamine, $50 \mu \mathrm{M}$ 2-Mercaptoethanol. To obtain activated lymphocytes, $20 \mu \mathrm{g} \mathrm{ml}^{-1}$ phytohemagglutinin-M (Roche Molecular Biochemicals) were added to culture, proliferating cells were collected after $48 \mathrm{~h}$, washed and seeded at $1 \times 10^{6}$ cells $\mathrm{ml}$.

\section{Cell survival assay}

A standard XTT assay (Roche Molecular Biochemicals, IN, USA) was used to determine cell survival. Cells were plated in 96-well plates at a density of $1 \times 10^{6}$ cells per ml (four wells per experimental condition), exposed to a range of concentrations of $4 \mathrm{HPR}$ and processed according to the manufacturer's instructions. In some experiments, $10 \mathrm{mM} \mathrm{N}$-acetyl-cysteine (NAC) or $100 \mu \mathrm{M}$ vitamin $\mathrm{E}$ (Sigma) were added $2 \mathrm{~h}$ before $4 \mathrm{HPR}$ addition. Absorbance at $480 \mathrm{~nm}$ was determined for each well, and cell survival percentages were calculated in each experiment in relation to controls-non treated-cells.

\section{Flow cytometry}

The Annexin V-FITC apoptosis detection kit (Calbiochem, Oncogene) was used to distinguish between apoptosis and necrosis. Cells were labelled after treatments according to the manufacturer's instructions and analysed by flow cytometry. Viable cells do not bind Annexin V-FITC or propidium iodide. Early apoptotic cells 
bind Annexin V-FITC but exclude propidium iodide. Necrotic and apoptotic cells in terminal stages (secondary necrosis) are both Annexin V-FITC and propidium iodide positive. Reduction of mitochondrial membrane potential was evaluated by Rhodamine 123 labelling (Molecular Probes, Eugene, OR, USA). After drug exposure cells were incubated with $5 \mu \mathrm{g} \mathrm{ml}^{-1} \mathrm{Rh} 123$ in RPMI 1640 containing $10 \%$ FCS for $30 \mathrm{~min}$ at $37^{\circ} \mathrm{C}$. Then cells were washed twice with PBS and incubated for 30 min with $10 \%$ FCS RPMI 1640. After washing, $5 \mu \mathrm{g} \mathrm{ml}^{-1}$ IP were added and viable cells were analysed by flow cytometry. At least 10000 viable cells per sample were individually analysed for quantitative fluorescence using a Coulter EPICS ELITE ESP flow cytometer (EPICS division Coulter Corp.).

\section{Western blotting}

Pellets were resuspended in Laemmli's SDS-PAGE sample buffer to a $1 \times$ and the viscosity of the lysates was reduced by shearing the DNA three times through a 26 needle. After boiling for $5 \mathrm{~min}, 30 \mu \mathrm{g}$ of each protein samples were subjected to electrophoresis in $15 \%$ polyacrylamide gels in the presence of $0.1 \%$ sodium dodecyl sulphate and transferred to nitrocellulose membranes. The nonspecific binding sites on the membrane were first blocked with $5 \%\left(\mathrm{w} \mathrm{v}^{-1}\right)$ dried milk in $20 \mathrm{mM}$ Tris- $\mathrm{HCl}$ ( $\mathrm{pH} 8.0$ ) containing $0.1 \%\left(\mathrm{v} \mathrm{v}^{-1}\right)$ Tween 20 (TTBS) for $1 \mathrm{~h}$ at room temperature. After three washes with TTBS, the membrane was incubated with anti-caspase-3, anti-bcl-2 (Santa Cruz Biotechnology, Inc., CA, USA) or anti-bax (R\&D Systems Minneapolis, MN, USA) antibodies diluted $1: 100$ in $2.5 \%\left(\mathrm{w} \mathrm{v}^{-1}\right)$ dried milk in TTBS for $90 \mathrm{~min}$ at room temperature. The membranes were then washed three times in TTBS, and incubated with anti-mouse or anti-rabbit IgG-peroxidase conjugate diluted $1: 3000$ in $1 \%$ $\left(\mathrm{w} \mathrm{v}^{-1}\right)$ dried milk in TTBS for $1 \mathrm{~h}$ at room temperature. The membrane was then washed four times with TTBS. The binding of the antibodies were probed by the chemiluminescence ECL method according to the manufacturer's instructions (Amersham Life Science Inc., Arlington Heights, IL, USA). For the detection of cytochrome $c$ release from mitochondria, cytosolic extracts were used. After treatments, cells were centrifugated, resuspended in buffer I (220 mM mannitol, $68 \mathrm{~mm}$ sucrose, $50 \mathrm{mM}$ PIPES-KOH $\mathrm{pH} 7.4,50 \mathrm{~mm} \mathrm{KCl}, 5 \mathrm{~mm}$ EGTA, $\left.2 \mathrm{~mm} \mathrm{MgCl}_{2}, 1 \mathrm{~mm} \mathrm{DTT}\right)$ and placed on ice during $10 \mathrm{~min}$. Cells were centrifugated at $1000 \mathrm{~g}$ for $5 \mathrm{~min}$ and then $30 \mu \mathrm{l}$ of buffer I supplemented with leupeptin $1 \mu \mathrm{g} \mathrm{ml}^{-1}$, aprotinin $1 \mu \mathrm{g} \mathrm{ml}^{-1}$, and pepstatin $1 \mu \mathrm{g} \mathrm{ml}^{-1}$ were used to suspend the cells. The cells were then disrupted by homogenisation on ice in a teflon dounce (100 strokes), the homogenate was subjected to centrifugation at $16000 \mathrm{~g}$ for $1 \mathrm{~min}$, and then the supernatant was collected and subjected to another centrifugation at $16000 \mathrm{~g}$ for $30 \mathrm{~min}$ to obtain a cytosolic extract. Samples of the cytosolic extracts containing $40 \mu \mathrm{g}$ protein were subjected to electrophoresis using $15 \%$ polyacrylamide gel, transferred and developed as described. Anticytochrome $c$ monoclonal antibody was purchased by BD Pharmingen (San Diego, CA, USA) and used at 1:500 dilution.

\section{Measurement of intracellular generation of ROS}

We used the oxidation-sensitive fluorescent dye $2^{\prime}, 7^{\prime}$-dichlorodihydrofluorescein diacetate (DCFH-DA, Molecular Probes, Eugene, OR, USA) to measure the production of reactive oxygen species, mainly hydrogen peroxide and hydroxyl radicals. Cells seeded in 96-well culture plates were exposed to $4 \mathrm{HPR}$ alone or in combination with antioxidants. Vitamin E $(100 \mu \mathrm{m})$ or NAC $(10 \mathrm{mM})$ were added $2 \mathrm{~h}$ before the drug. In some cultures (see Figure 6) the following inhibitors were added in combination with 4HPR: the uncoupler, carbonylcyanide m-chlorophenylhydrazone (CCCP) $10 \mu \mathrm{M}$; NADPH inhibitor DPI $2 \mathrm{~mm}$; xanthine/xanthine oxidase inhibitor, allopurinol $1 \mathrm{mM}$; MRC complex II inhibitor, thenoyltri- fluoroacetone (TTFA) $1 \mathrm{mM}$; MRC complex III inhibitor, antimycin A $2 \mu \mathrm{g} \mathrm{ml}^{-1}$ (all were purchased from Sigma Chemical Co). After $30 \mathrm{~min}$ cells were washed and incubated at $37^{\circ} \mathrm{C}$ with $10 \mu \mathrm{g} \mathrm{ml}^{-1}$ DCFC-DA for $20 \mathrm{~min}$. After washing twice, fluorescence intensity was measured at $530 \mathrm{~nm}$ after excitation at $485 \mathrm{~nm}$ in a FL500 fluorimeter (Bio-Tek Instruments). Four wells were used for each treatment.

\section{Measurement of cardiolipin peroxidation}

10-N-nonyl-Acridin Orange (NAO, Molecular Probes, Inc.), which binds to mitochondria-specific cardiolipin, was used for this purpose. Decreases in the fluorescence of NAO in apoptotic cells have been reported to reflect the peroxidation of intracellular cardiolipin (Nomura et al, 2000) because the fluorochrome loses its affinity for peroxidised cardiolipin. Cells were seeded at a final concentration of $1 \times 10^{6} \mathrm{cells} \mathrm{ml}^{-1}$ in 96-well tissue culture plates, treated with different concentrations of $4 \mathrm{HPR}$, washed and labelled with $10 \mu \mathrm{g} \mathrm{ml}^{-1} \mathrm{NAO}$ for $20 \mathrm{~min}$. In some cultures $100 \mu \mathrm{M}$ vitamin $\mathrm{E}$ was added $2 \mathrm{~h}$ before $4 \mathrm{HPR}$ addition. After washing twice, fluorescence emited by cardiolipin-bounded NAO was measured at $530 \mathrm{~nm}$-excitation at $485 \mathrm{~nm}$-in a FL500 fluorimeter (Bio-Tek Instruments). Four wells were used for each experimental condition.

\section{Statistics}

The results were expressed as the mean \pm s.d of at least three independent experiments. Student's two-tailed, unpaired $t$-test was used, and values of $P<0.05$ were considered to be significant.

\section{RESULTS}

A dose-time study was carried out to establish the effect of 4HPR in the survival rate of CCRF-CEM cells (Figure 1). The lower concentration in which maximum cell death was achieved was $3 \mu \mathrm{M}$, a concentration known to be attainable in vivo (Formelli et al, 1993). At this dose, nearly $90 \%$ of the cells were eliminated in $24 \mathrm{~h}$. However, neither normal nor activated peripheral lymphocytes were affected under these conditions (Figure 2). Only the maximum concentration tested $-10 \mu \mathrm{M} 4 \mathrm{HPR}$ - had some effect on the survival of normal lymphocytes, being the latter much more resistant to the drug than malignant cells.

4HPR-induced cell death in lymphoblastoid leukaemia cells is caused by apoptosis at pharmacological concentrations (Figure $3 \mathrm{~A}$ ), but proceeds predominantly by necrosis at higher drug concentrations $(10 \mu \mathrm{M})$. Ultrastuctural images have confirmed that the enhancement of necrosis percentages is mainly due to secondary necrosis (apoptotic cells in terminal stages) rather than real necrosis. These results are in concordance with the observation that caspase 3 is activated in cells treated with 4HPR (Figure 3B). The blot revealed a progressive cleavage of pro-caspase 3 in the course of time. However, no changes in the expression of apoptosisrelated proteins Bcl-2 and Bax have been observed (Figure 3C).

Measurements of cellular fluorescence revealed that $4 \mathrm{HPR}$ induced an immediate ROS elevation in CCRF-CEM cells. After $30 \mathrm{~min}$ of exposure, a dose-dependent increase in the amount of ROS was observed (Figure 4). The enhancement of ROS was much higher after 45-60 min of exposure when 4.0-fold increase in ROS was observed at higher doses, and was noticeable just after $5 \mathrm{~min}$ of treatment (data not shown). This oxidative stress was inhibited with antioxidants such as $\mathrm{N}$-acetyl-cysteine (NAC) and vitamin $\mathrm{E}$, being the latter more effective at neutralising reactive oxygen species (Figure 4). These antioxidants that are effective at suppressing HPR-induced ROS are also effective at reducing 4HPRinduced apoptosis (Figure 5). Curiously, vitamin E-which is more powerful than NAC scavenging ROS generated by $4 \mathrm{HPR}$-is also more effective at reducing drug induced cell death. In this sense, 


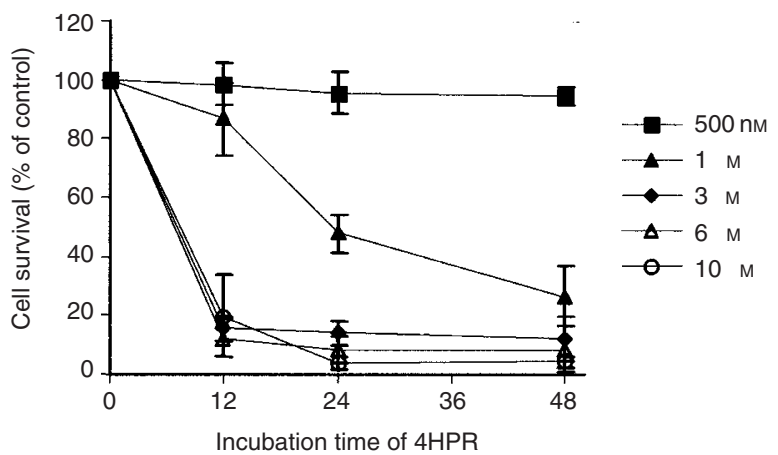

Figure I Dose- and time-dependent effect of $4 \mathrm{HPR}$ on cell survival of human CCRF-CEM cells. The mean \pm s.d of three independent experiments are shown.

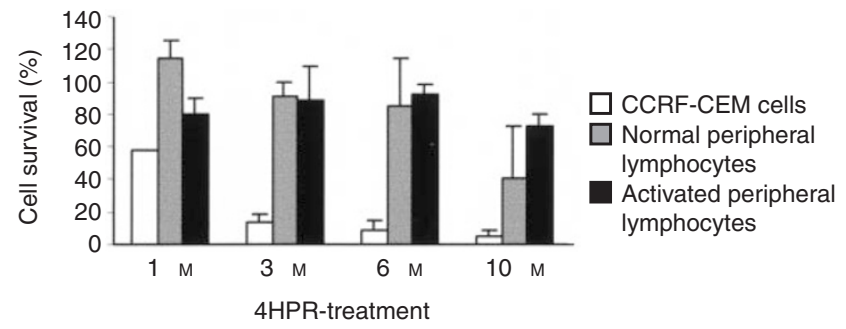

Figure 2 Effect of 4HPR on of peripheral lymphocytes and malignant CCRF-CEM cells survival. Percentages of cells treated for $24 \mathrm{~h}$ with increasing doses of $4 \mathrm{HPR}$ are shown. The mean \pm s.d of three independent experiments are shown.

vitamin $\mathrm{E}$ is able to completely inhibit cell death induced by $1 \mu \mathrm{M}$ of $4 \mathrm{HPR}$, and reverts from 10 to $75 \%$ the cell death induced by $3 \mu \mathrm{M}$ 4HPR. Results indicate that the antioxidants effect on HPR-induced apoptosis is related with their ability to suppress the enhancement of ROS in 4HPR-treated malignant cells. In contrast, our assays failed to prove enhancement of ROS on $4 \mathrm{HPR}$-treated normal and activated peripheral lymphocytes (data not shown).

To analyse the origin of $4 \mathrm{HPR}$-induced reactive oxygen species, the effect of some radical-producing system inhibitors was tested in the presence of 4HPR (Figure 6). Allopurinol-xanthine/xanthine oxidase inhibitor - and DPI-NADPH oxidase inhibitor-, have no effect on 4HPR-induced ROS increase. However, CCCP, which uncouples electron transfer in mitochondria and inhibits the generation of ROS from MRC, suppressed completely 4HPRinduced oxidative stress. Among the inhibitors of MRC complexes tested, only TTFA-an MRC complex II inhibitor-completely suppressed 4HPR-induced ROS elevation. The MRC complex I inhibitor rotenone inhibited 4HPR-induced ROS generation by $52 \%$, but none of the other inhibitors used (antimycin A which inhibits complex III and azide which inhibits complex IV) caused any effect over the ROS production. These results indicate that 4 HPR stimulated ROS production upstream of complex III, preferentially between complexes II and III.

To study if peroxidation of cardiolipin (CL) took place in $4 \mathrm{HPR}$-treated cells, binding of $\mathrm{NAO}-\mathrm{a}$ fluorescent probe that binds specifically to CL - was measured in treated CEM cells (Table 1). Results showed a dose- and time-dependent decrease of NAO binding to 4 HPR-treated cells (Table 1), which reflect the peroxidation of mitochondrial CL. Fluorochrome binding reduction was significant after $2 \mathrm{~h}$ of $4 \mathrm{HPR}$-treatment with reference to non treated cells, and a decrease of $50-60 \%$ in NAO binding was observed at high doses $(10 \mu \mathrm{M})$. At lower doses $(3 \mu \mathrm{M})$, about $50 \%$ of NAO binding capacity to CL is lost as early as at $6 \mathrm{~h}$ of
A

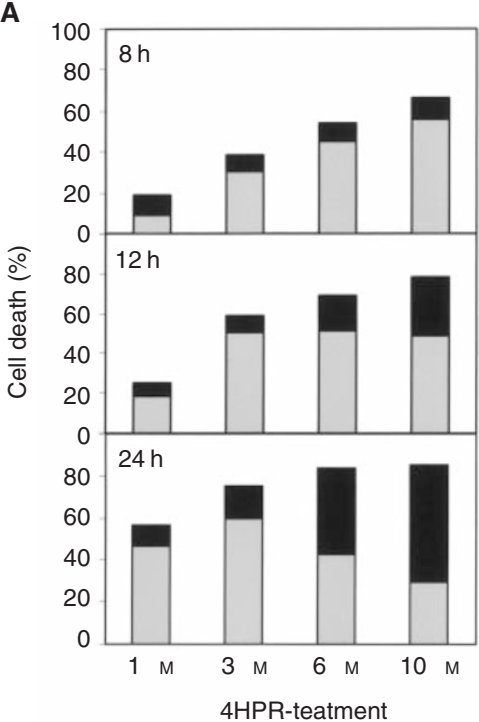

B
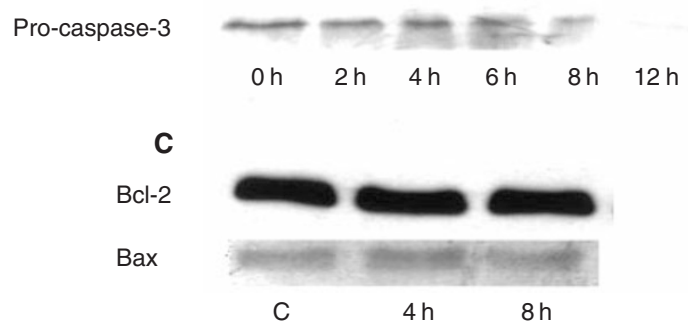

Figure 3 (A) Apoptosis and necrosis rates in 4HPR-treated CCRFCEM cells. Cells were treated with increasing doses of 4HPR for 8, 12 and $24 \mathrm{~h}$ and then labelled with Annexin- $V$ and Propidium lodide as described in Materials and Methods. Apoptosis percentages are represented in grey, and in black percentages of necrotic cells in the same cultures. (B) Activation of caspase-3 in 4HPR-treated human CCRF-CEM cells. Blot shows the progressive pro-caspase-3 cleavage along time in $10 \mu \mathrm{M} 4 \mathrm{HPR}$-treated cells. (C) Bcl-2 and Bax protein expression in control and 4HPR-treated CEM cells.

exposure. The antioxidant vitamin E reduces CL peroxidation in all cases, and it is more effective preventing the oxidation induced by lower doses of $4 \mathrm{HPR}$. It is important to note that mitochondrial transmembrane potential reduction-measured by Rhodamine 123 labelling-was not observed until $4 \mathrm{~h}$ after exposure to drug (Figure 7). Thus, CL peroxidation precedes mitochondrial potential reduction.

$4 \mathrm{HPR}$ induces a release of cytochrome $c$ from mitochondria in CEM cells and the amount of cytochrome $c$ detected in the cytosol was increasing along the 4HPR-treatment time $(0,2,8$ and $12 \mathrm{~h}$ ) (Figure 8). Moreover, this release is clearly reduced in all cases when the vitamin $\mathrm{E}$ is added to the cultures. This result shows that $4 \mathrm{HPR}$ induces cytochrome $c$ release in an antioxidant-sensitive pathway.

\section{DISCUSSION}

Our results indicate that at pharmacological doses, 4HPR causes apoptosis in human acute lymphoblastoid leukaemia cells CCRF-CEM (Figure 3A,B), and that its proapoptotic properties are related with the ability to produce ROS at mitochondrial level. The increase in ROS has been proposed as one mechanism through which 4HPR could exert its proapoptotic effects (Delia et al, 1997; 


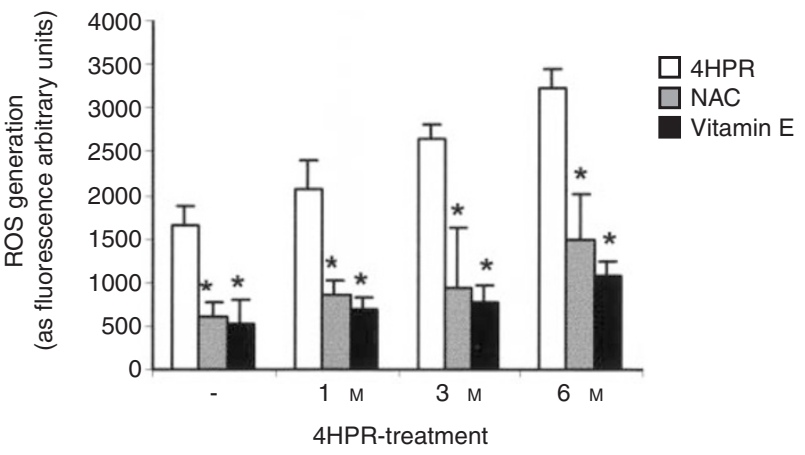

Figure 4 Effect of antioxidants on the generation of reactive oxygen species in 4HPR-treated CCRF-CEM cells. A dose-dependent study. Cells were treated with or without increasing doses of $4 \mathrm{HPR}$ for $30 \mathrm{~min}$ and then ROS production was measured. In some cultures, the antioxidants NAC and vitamin $\mathrm{E}$ were added $2 \mathrm{~h}$ before initiating the treatments. The mean \pm s.d. of three experiments are shown. Differences in ROS production between antioxidant-treated cells and non-treated cells were statistically significant $(P<0.01)$.

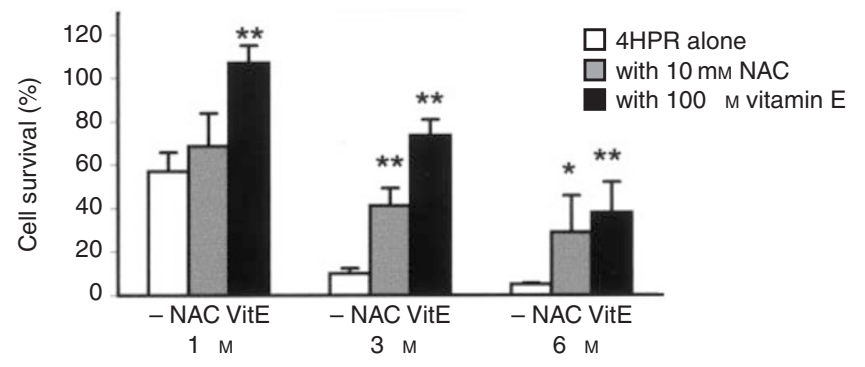

Figure 5 Effect of antioxidants on the survival of 4HPR-treated CEM cells. Cells were treated with 4HPR alone, or in combination with $10 \mathrm{mM}$ NAC or $100 \mu \mathrm{M}$ vitamin E. Relative percentages with respect to non-treated cells are shown. The means \pm s.d. of three experiments are shown. Differences in cell survival of antioxidant-treated cells were statistically significant with reference to those only treated with 4 HPR ( ${ }^{*} P<0.05$; *** $P<0.01)$.

Maurer et al, 1999; Suzuki et al, 1999; Wu et al, 2001). The fact that antioxidants NAC and vitamin E decrease both 4HPR-induced ROS production (Figure 4) and cell death (Figure 5), demonstrate that ROS are critical in mediating apoptosis in CEM cells. Also, our studies revealed that $4 \mathrm{HPR}$ exerts different effects on either malignant lymphoblasts or normal lymphocytes. 4HPR does not stimulate ROS production on normal or activated peripheral lymphocytes, and subsequently these cells seem to be significantly more resistant to 4HPR than tumour cells (Figure 2). This specificity of retinamide towards malignant cells and not normal cells confers $4 \mathrm{HPR}$ an important characteristic as a therapeutic agent. The more or less sensitivity of cells to $4 \mathrm{HPR}$ may be due to the status of endogenous antioxidant systems. The major source of ROS in eukariotic cells are the mitochondrial respiratory chain components (Fernández-Checa et al, 1998), and the radical-generating enzymes xanthine/xanthine oxidase (McCord, 1985) and NADPH oxidase (Trudel et al, 1991). Among all inhibitors of such ROS source used, only those exerting their action on mitochondria have some effect on the 4HPR-induced oxidative stress (Figure 6). Blocking ATP synthesis and ROS generation by MRC with CCCP an uncoupler of electron transfer-4HPR-induced oxidative stress is completely reduced, which indicates mitochondrial participation. In this sense Hail and Lotan (2001) have demonstrated recently that the pro-oxidant effect of $4 \mathrm{HPR}$ is associated with mithochon-

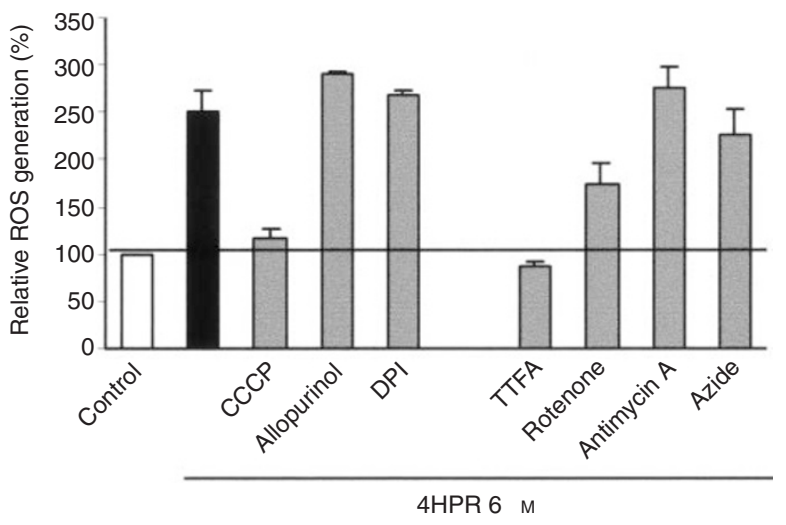

Figure 6 Effects of various inhibitors on the 4HPR-induced ROS generation in CCRF-CEM cells. Cells were treated with 4HPR and/or inhibitors for $30 \mathrm{~min}$ and then ROS generation was measured. Relative percentages with respect to controls (basal production, white bar) are shown. The black bar represents ROS production of 4 HPR treated cells. The mean \pm s.d. of three independent experiments is shown.

drial redox metabolism in human cutaneous carcinoma cells. To reinforce the finding that electron flow at MRC is the major site of ROS generation by $4 \mathrm{HPR}$, we inhibited electron flow at complexes I to IV, and the results illustrated that ROS generation source is probably located downstream MRC complexes I and II, and upstream complex III (Figure 6). These results are in accordance with those reported by Suzuki et al (1999) in cervical carcinoma cells, which point to a target site of 4HPR action in ROS generation located between complexes II and III. Additional studies are required to determine whether ROS increase at these sites is a general phenomenon or not in 4HPR-induced apoptosis.

Nowadays it is generally accepted that alterations of the mitochondrial function, such as a reduction of the inner transmembrane potential and release of proteins through the outer membrane, constitute an important feature of apoptosis. Our studies show that in $4 \mathrm{HPR}$ treated cells, ROS enhancementperceptible just after $5 \mathrm{~min}$ but significant after $30 \mathrm{~min}$-is generated earlier than mitochondrial membrane reduction (observed after $4 \mathrm{~h}$, Figure 7). Therefore, it is likely that mitochondrial alterations observed are due to the direct action of 4HPR-induced ROS. ROS are able to open mitochondrial transition pores leading to an interruption of mitochondrial potential and release of apoptogenic factors (Kroemer et al, 1997). However, the mechanism responsible is not defined. Pro- and anti-apoptotic members of the Bcl-2 family can control the mitochondrial transition pores in some systems (Loeffler and Kroemer, 2000). No participation of Bcl-2/ Bax in 4HPR-induced cell death was observed in our studies (Figure 3C). Expression of other proteins tested such as Bak and $\mathrm{Bcl}$-xl also remain unaltered in 4HPR-treated CEM cells (data not shown). Lipid peroxidation, which is known to occur during cell death after stimulation with pro-oxidants (Fernández-Checa et al, 1998; Nomura et al, 2000), could be one of the causes that originate mitochondrial dysfunction. Our results show that 4HPR-induced mitochondrial ROS increase is the cause of cardiolipin peroxidation as early as $2 \mathrm{~h}$ after $4 \mathrm{HPR}$ treatment (Table 1), before reduction of mitochondrial membrane potential was evident (Figure 7). Cardiolipin-which is located exclusively in the inner mitochondrial membrane-, has a pivotal role as the boundary lipid of various proteins such as NADH:ubiquinone oxidoreductase, cytochrome $c$ oxidase and cytochrome $c$ (Hoch, 1992). Specifically, cytochrome $c$ associates strongly with cardiolipin. A linkage between mitochondrial lipid peroxidation and cytochrome $c$ release has been recently established (Nomura et al, 2000). Nomura et al (2000) have shown that peroxidation of CL in the 
Table I Effect of 4HPR-treatment on NAO binding in CCRF-CEM cells

\begin{tabular}{|c|c|c|c|c|c|c|}
\hline \multirow[b]{3}{*}{4 HPR-concentration } & \multicolumn{6}{|c|}{ Time of 4HPR exposure } \\
\hline & \multicolumn{2}{|c|}{$2 \mathrm{~h}$} & \multicolumn{2}{|c|}{$4 \mathrm{~h}$} & \multicolumn{2}{|c|}{$6 \mathrm{~h}$} \\
\hline & - & Vit E & - & Vit E & - & Vit E \\
\hline $\mathrm{I} \mu \mathrm{M}$ & $76.2 \pm 1.5$ & $92.9 \pm 6.8^{*}$ & $67.6 \pm 1.2$ & $97.7 \pm 9.2 *$ & $62.3 \pm 5.9$ & $86.0 \pm 9.7 *$ \\
\hline $3 \mu \mathrm{M}$ & $74.6 \pm 3.3$ & $97.8 \pm 7.2 *$ & $64.9 \pm 2.7$ & $86.5 \pm 1.3 *$ & $50.9 \pm 2.3$ & $73.5 \pm 6.5^{*}$ \\
\hline $6 \mu \mathrm{M}$ & $62.4 \pm 9.3$ & $82.9 \pm 3.9 *$ & $59.2 \pm 6.9$ & $73.0 \pm 0.4 *$ & $49.9 \pm 8.2$ & $62.2 \pm 4.2 *$ \\
\hline $10 \mu \mathrm{M}$ & $54.3 \pm 6.0$ & $73.3 \pm 1.7$ & $44.1 \pm 7.9$ & $58.6 \pm 10.5$ & $39.9 \pm 0.8$ & $49.1 \pm 7.6$ \\
\hline
\end{tabular}

In some cultures, vitamin $\mathrm{E}$ was added $2 \mathrm{~h}$ before addition of $4 \mathrm{HPR}$. Data are expressed as relative percentages of the fluorescence emitted by bound NAO with respect to non treated control cells ( $100 \%)$. the mean \pm s.d. of three experiments are shown. Note that 4HPR treatment gives rise to a decrease in NAO binding, which is related with cardiolipin peroxidation. Differences in NAO binding of antioxidant-treated cells were statistically significant with respect to those only treated with $4 \mathrm{HPR}\left({ }^{*} P<0.05\right)$

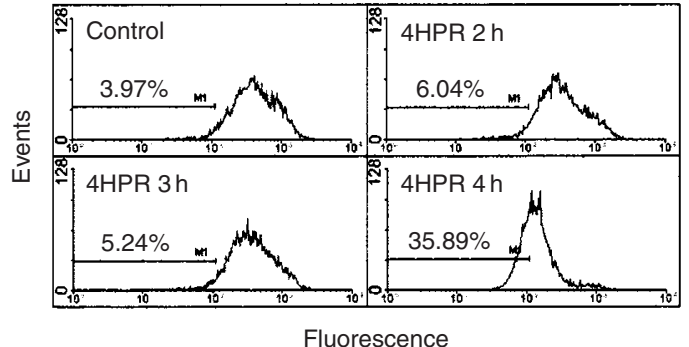

Figure 7 Mitochondrial membrane potential in CCRF-cells treated with 4HPR. Cells treated with $6 \mu \mathrm{g} \mathrm{ml} l^{-1}$ 4HPR during short periods of time (I, 3 and 4 h) were labelled with Rhodamine 123 and analysed by flow cytometry. The reduction of transmembrane potential after $4 \mathrm{~h}$ of treatment is represented as a shift of the fluorescence peak to lower levels and the percentage of cells in the lower fluorescence category was plotted in the graphs.

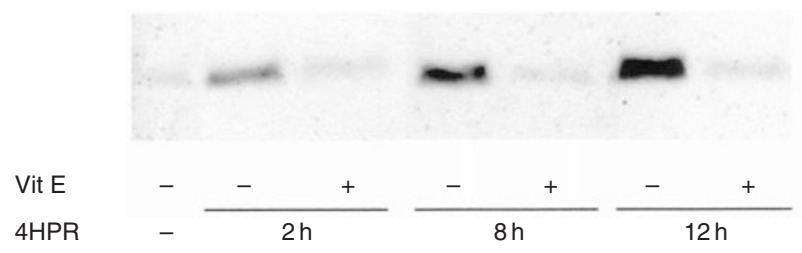

Figure 8 Effect of vitamin E on 4HPR-induced cytochrome $c$ release in human CCRF-CEM cells. Cells were incubated without (control) or with $5 \mu \mathrm{M} 4 \mathrm{HPR}$ during 2,8 and $12 \mathrm{~h}$. In some cultures vitamin $\mathrm{E}$ was added $2 \mathrm{~h}$ before addition of $4 \mathrm{HPR}$.

mitochondria resulted in the dissociation of cytochrome $c$ from mitochondrial inner membranes, the initial step in the release of cytochrome $c$ to cytosol. Furthermore, cardiolipin is essential for the activity of ANT (adenine nucleotide translocator) (Hoffmann et al, 1994), a protein of permeability transition pores, and there-

\section{REFERENCES}

Delia D, Aiello A, Lombardi L, Pelicci G, Grignani F, Grignani F, Formelli F, Menard S, Costa S, Costa A, Veronesi U, Pierotti MA (1993) N-(4-Hydroxyphenyl)retinamide induces apoptosis of malignant hemopoietic cell lines including those unresponsive to retinoic acid. Cancer Res 53: 6036-6041

Delia D, Aiello A, Meroni L, Nicolini M, Reed JC, Pierotti MA (1997) Role of antioxidants and intracellular free radicals in retinamide-induced cell death. Carcinogenesis 18: $943-948$

Fernández-Checa JC, García-Ruiz C, Colell A, Morales A, Marí M, Miranda M, Ardite E (1998) Oxidative stress: role of mitochondria and protection by glutathione. BioFactors $8: 7-11$ fore cardiolipin peroxidation could explain why ROS are able to open the mitochondrial permeability transition pores. Release of cytochrome $c$, which occurs following a variety of death stimuli, has been shown to activate Apaf-1 (apoptotic protease-activating factor 1), which in turn activates caspases-9 and -3 (Li et al, 1997; Zou et al, 1997) that finally dismantle the cell. It now seems likely that cardiolipin peroxidation caused by $4 \mathrm{HPR}$-induced ROS (Table 1) triggers cytochrome $c$ release (Figure 7) and, in consequence, the observed caspase-3 activation (Figure 3). Reinforcing this idea is the finding that vitamin $\mathrm{E}$-whose major function is to protect the polyunsaturated membrane lipids against free radical attack-appears to be more effective against 4HPR-induced apoptosis than other antioxidants tested (Figure 5). Furthermore, we have demonstrated that Vitamin $\mathrm{E}$ was able to reduce clearly the CL peroxidation (Table 1 ) and cytochrome $c$ release (Figure 7 ) in 4HPR-treated cells and therefore, these events occurred later than ROS generation. However, we cannot exclude the possibility that other actions of ROS-different from that concerning mitochondria membranes-contribute to caspase activation and therefore to 4HPR-induced cell death.

In summary, our results suggest a linkage between ROS generation at the MRC (between complexes II and III), cardiolipin peroxidation, cytochrome $c$ release and caspase- 3 activation in 4HPR-induced apoptosis.

\section{ACKNOWLEDGEMENTS}

This study is dedicated to the loving memory of our colleague and friend Manuel García Sanz, who sadly passed away last November 2000. 'We'd like to thank you very much for your valuable assistance at all times, for being such an excellent professional and better person. We miss you'. This study was supported by Grants from the Goverment of The Basque Country (PI-1999-127) and University of The Basque Country (UPV 00075.125-E-13694/ 2001). Celia Morales is supported by a fellowship from the Spanish Ministery of Education and Culture.

Formelli F, Clerici M, Campa T, Di Mauro MG, Magni A, Mascotti G (1993) Five-year administration of fenretinide: pharmacokinetics and effects on plasma retinol concentrations. J Clin Oncol 11: 2036-2042

Hail N, Lotan R (2001) Mitochondrial respiration is uniquely associated with the prooxidant and apoptotic effects of $\mathrm{N}$-(4-hydroxyphenyl)retinamide. $J$ Biol Chem 276: 45614-45621

Hoch FL (1992) Cardiolipins and biomembrane function. Biochim Biophys Acta 1113: $71-133$ 
Hoffmann B, Stocki A, Schlame M, Beyer K, Klingerberg M (1994) The reconstituted ADP/ATP carrier activity has an absolute requirement for cardiolipin as shown in cysteine mutants. J Biol Chem 269: $1940-$ 1944

Kalemkerian GP, Slusher R, Sakkaraiappan R, Gadgeel S, Mabry M (1995) Growth inhibition and induction of apoptosis by fenretinide in small-cell lung cancer cell lines. J Nat Cancer Inst 87: 1674-1680

Kroemer G, Zamzami N, Susin SA. (1997) Mitochondrial control of apoptosis. Immunol Today 18: $44-51$

Li P, Nijhawan D, Budihardjo I, Srinivasula SM, Ahmad M, Alnemri ES, Wang X (1997) Cytochrome c and dATP-dependent formation of Apaf1/caspase-9 complex initiates an apoptotic protease cascade. Cell 91: $479-489$

Loeffler M, Kroemer G (2000) The mitocondrion in cell death control: certainties and incognita. Exp Cell Res 256: 19-26

Maurer BJ, Metelitsa LS, Seeger RC, Cabot MC, Reynolds P (1999) Increase of ceramide and induction of mixed apoptosis/necrosis by N-(4-Hydroxyphenyl)-retinamide in neuroblastoma cell lines. J Natl Cancer Inst 91: $1138-1146$

McCord JM (1985) Free radicals and myocardial ischemia. The role of xanthine oxidase. $N$ Eng J Med 312: 159-163
Nomura K, Imai T, Kobayashi T, Nakagawa Y (2000) Mitochondrial phospholipid hydroperoxide glutathione peroxidase inhibits the release of cytochrome $c$ from mitochondria by suppressing the peroxidation of cardiolipin in hypoglycaemia-induced apoptosis. Biochem J 351: 183-193

Sun S-Y, Li W, Yue P, Lippman SM, Hong WK, Lotan R (1999) Mediation of $\mathrm{N}$-(4-Hydroxyphenyl)retinamide-induced apoptosis in human cancer cells by different mechanisms. Cancer Res 59: 2493-2498

Suzuki S, Higuchi M, Proske RJ, Oridate N, Hong WK, Lotan R (1999) Implication of mitochondria-derived reactive oxygen species, cytochrome $\mathrm{c}$ and caspase-3 in N-(4-Hydroxyphenyl)retinamide-induced apoptosis in cervical carcinoma cells. Oncogene 18: 6380-6387

Trudel S, Paquet MR, Grinstein S (1991) Mechanism of vanadate-induced activation of tyrosine phosphorylation and of the respiratory burst in HL60 cells. Role of reduced oxygen metabolites. Biochem J 276: 611-619

Ulukaya E, Wood EJ (1999) Fenretinide and its relation to cancer. Cancer Treat Rev 25: 229-235

Wu JM, DiPietrantonio AM, Hsieh TC (2001) Mechanism of fenretinide (4HPR)-induced cell death. Apoptosis 6: $377-388$

Zou H, Henzel WJ, Liu X, Lutschg A, Wang X (1997) Apaf-1, a human protein homologous to C. elegans CED-4, participates in cytochrome cdependent activation of caspase-3. Cell 90: 405-413 